\title{
Development of a rotation free shell finite element for modeling shell structures
}

\author{
Bachir Labiodh ${ }^{a^{*}}$, Djamal Hamadi ${ }^{a}$ and Abdallah Zatar ${ }^{a}$
}

${ }^{a}$ Laboratory LARGHYDE, Biskra University, Algeria

\begin{tabular}{l}
\hline A R T I C L EI N F O \\
\hline Article history: \\
Received 28 Februrary 2019 \\
Accepted 23 September 2019 \\
Available online \\
23 September 2019 \\
\hline Keywords: \\
Shell finite element \\
Modeling \\
Rotation degree of freedom \\
Junction \\
Solid-shells
\end{tabular}

\section{Introduction}

Among the modeling problems existing in the study of structures using finite elements, we find the question relating to the connection of finite elements of the shell type with solid elements, indeed the number of degrees of freedom in the connection zone of the elements is not identical. The solid element has three translations while the shell element has three translations plus three rotations. In the literature there exist a some number of finites elements which are conceived to solve this type of problems, as an example the solid-shell element type which have shell behavior; but with a three-dimensional geometry. These elements allow combining characteristics of solid elements such as the geometrical description and the degrees of freedom to the mechanical models which uses the theories of the shells. Among these elements, the three dimensional shell elements developed by Ahmad et al. (1970), these models named degenerated three-dimensional finite elements and are based on isoparametric solid elements and having only two nodes according to the thickness direction. Another shell element with hexahedral geometry named SHB8PS developed by Abed-Meraim and Combescure (2002), this solid element is derived from a purely three-dimensional formulation and can be used to model thick shells. Hamadi (2006) developed a parallelepiped element named SBP8C and based on the strain approach formulations, it can be used for

\footnotetext{
* Corresponding author. Tel:+213 662721048

E-mail addresses: labiodhbachir@gmail.com (B. Labiodh)
}

(C) 2020 Growing Science Ltd. All rights reserved. doi: $10.5267 /$ j.esm.2019.9.006 
modeling the three dimensional structures and also for the problems of bending of the thin and thick plates, the results are very acceptable.

Contrary to solid-shell element which can be used for analyzing thin and thick structures, there are two dimensional shell elements without degrees of freedom of rotation and can be used to model only the thin parts of the structure for connection in the zone of junction between thin and thick structures. In addition to the advantage of the coherence of the degrees of freedom between the shell elements and solids, these elements have less number of degrees of freedom than other solid elements and do not suffer from locking shear-bending phenomenon. These elements also present the advantageous conditioning of stiffeners matrix which improves as the thickness decreases. As an example of these type of elements, the DKTRF element (Guo et al., 2002) which is obtained by derivation from the triangular element DKT12 (Batoz \& Dhatt, 1992) where the rotations of the inside nodes are expressed in the terms of the eighteen translation degrees of per node. Another element called S3 formulated by Crisfield and Peng (1992) and then is more improved by Sabourin and Brunet (2006), it constructed starting from the triangular element of Morley (1971) and Oñate et al. (1989) is introduced the Bending into a triangular element of membrane without addition the rotation degree of freedom. This strategy was developed and used by Rio et al. (1993) like Brunet and Sabourin (1994, 1995). Mercier (1998) used the triangular element DKT12 obtained by superposition of elements CST and DKT6, the obtained element takes into account both membrane and bending effects without degrees of rotations., i.e. the three medium side rotations of the element DKT6 are eliminated. Finally, we should mention that other finite elements of shells types without rotations are published by Oñate and Flores (2005) and Oñate et al. (2007).

This paper presents the formulation of a triangular finite element called DKT18RF, is a shell type element without rotation degree of freedom and is obtained by derivation from the flat shell element DKT18 developed by Batoz and Dhatt (1992). This element is the result of the superposition of the triangular element of membrane CST which contains two degrees of freedom per node and the plate bending element DKT which contains three degree of freedom per node, two rotations and one vertical deflection. The principal idea in this work consists of modifying the deformation matrix expresses the bending effects of DKT element; so that it does only contain the terms represent the bending effect. The superposition of element DKT modified with the membrane CST element gives the called DKT18RF finite element with only three translations per node. This element is programmed under MATLAB in order to test its performance and efficiency through the different test available in the literature.

\section{Formulation of DKT18RF element}

While basing on the triangular element of type flat shell element DKT18, which is constructed by superposition of membrane element CST includes two in plane degrees of freedom (U, V) as nodal variables, and the discrete Kirchhoff element DKT which has three nodal variables (W, $\theta \mathrm{x}, \theta \mathrm{y})$. By addition of a fictitious in plane rotation $\theta z$, and after assembling these two elements to obtains a flat shell element with the three translation displacements $(\mathrm{U}, \mathrm{V}, \mathrm{W})$ and three nodal rotations $\left(\theta_{\mathrm{X}}, \theta_{\mathrm{Y}}, \theta_{\mathrm{Z}}\right)$ around the axes $\mathrm{X}, \mathrm{Y}$ and $\mathrm{Z}$, respectively, we will formulate the triangular element called DKT18RF. Following the same procedure of superposition procedure, the membrane part is represented by the linear element CST which contains the nodal variables $(\mathrm{U}, \mathrm{V})$, and the bending part by the element DKT contains only lateral nodal variable (W). This superposition is illustrated in Fig. 1. 


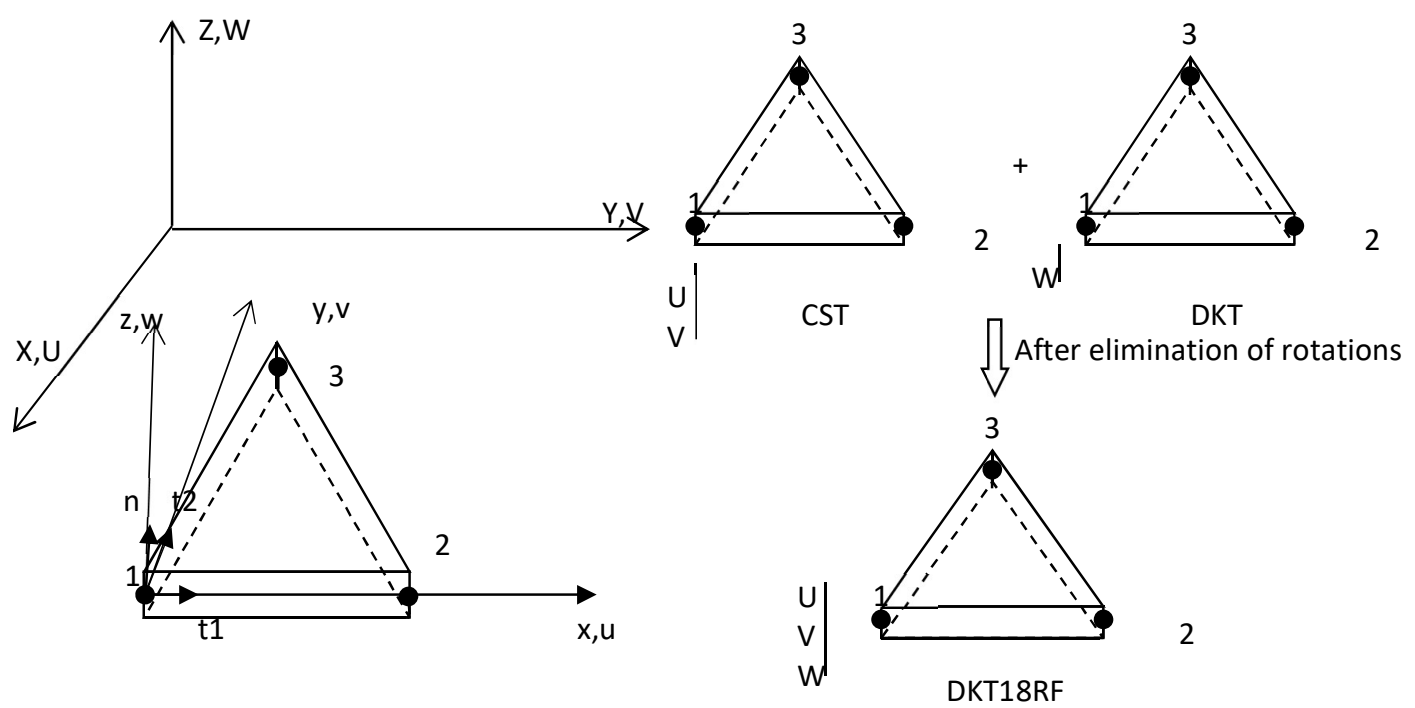

Fig. 1. Construction of DKT18RF element after elimination of rotations

\subsection{Definition of the local system reference coordinates}

The surface of reference of the element is defined by

$$
\left\{\mathrm{x}_{\mathrm{p}}\right\}=\left\{\begin{array}{l}
\mathrm{X} \\
\mathrm{Y} \\
\mathrm{Z}
\end{array}\right\}=\sum_{\mathrm{i}=1}^{3} \mathrm{~N}_{\mathrm{i}}\left\{\begin{array}{l}
\mathrm{X}_{\mathrm{i}} \\
\mathrm{Y}_{\mathrm{i}} \\
\mathrm{Z}_{\mathrm{i}}
\end{array}\right\}
$$

The interpolation functions $\mathrm{N}_{\mathrm{i}}$ are given by

$$
\mathrm{N}_{1}=\lambda=1-\xi-\eta, \mathrm{N}_{2}=\xi, \mathrm{N}_{3}=\eta
$$

The basic vectors $\mathrm{a}_{1}$ and $\mathrm{a}_{2}$ are

$$
\left\{\mathrm{a}_{1}\right\}=\left\{\mathrm{x}_{\mathrm{p}, \xi}\right\}=\left\{\begin{array}{l}
\mathrm{X}_{21} \\
\mathrm{Y}_{21} \\
\mathrm{Z}_{21}
\end{array}\right\},\left\{\mathrm{a}_{2}\right\}=\left\{\mathrm{x}_{\mathrm{p}, \eta}\right\}=\left\{\begin{array}{l}
\mathrm{X}_{31} \\
\mathrm{Y}_{31} \\
\mathrm{Z}_{31}
\end{array}\right\}
$$

The local axes reference can be defined as

$$
\begin{aligned}
& {[\mathrm{Q}]=\left[\begin{array}{lll}
\mathrm{t}_{1} & \mathrm{t}_{2} & \mathrm{n}
\end{array}\right]} \\
& \mathrm{n}=\frac{\mathrm{a}_{1} \wedge \mathrm{a}_{2}}{\left|\mathrm{a}_{1} \wedge \mathrm{a}_{2}\right|}, \mathrm{t}_{1}=\frac{\mathrm{a}_{1}}{\mathrm{~L}_{21}}, \mathrm{t}_{2}=\mathrm{n} \wedge \mathrm{t}_{1} \\
& \mathrm{~L}_{21}=\left(\mathrm{X}_{21}^{2}+\mathrm{Y}_{21}^{2}+\mathrm{Z}_{21}^{2}\right)^{\frac{1}{2}}
\end{aligned}
$$

Where

$$
\mathrm{X}_{21}=\mathrm{X}_{2}-\mathrm{X}_{1}, \mathrm{Y}_{21}=\mathrm{Y}_{2}-\mathrm{Y}_{1}, \mathrm{Z}_{21}=\mathrm{Z}_{2}-\mathrm{Z}_{1}
$$




$$
\{n\}=\left\{\begin{array}{l}
n_{X} \\
n_{Y} \\
n_{Z}
\end{array}\right\}=\frac{1}{2 A}\left\{\begin{array}{l}
Y_{21} Z_{31}-Y_{31} Z_{21} \\
Z_{21} X_{31}-Z_{31} X_{21} \\
X_{21} Y_{31}-X_{31} Y_{21}
\end{array}\right\}
$$

The surface of element A

$$
2 A=\left(\left(Y_{21} Z_{31}-Y_{31} Z_{21}\right)^{2}+\left(Z_{21} X_{31}-Z_{31} X_{21}\right)^{2}+\left(X_{21} Y_{31}-X_{31} Y_{21}\right)^{2}\right)^{\frac{1}{2}}
$$

$t_{1}$ and $t_{2}$ can be also calculated by

$$
\begin{aligned}
& \left\langle\mathrm{t}_{1}\right\rangle=\left\langle\mathrm{n}_{\mathrm{Z}}+\frac{\mathrm{n}_{\mathrm{Y}}^{2}}{\mathrm{a}} \frac{-\mathrm{n}_{\mathrm{X}} \mathrm{n}_{\mathrm{Y}}}{\mathrm{a}}-\mathrm{n}_{\mathrm{X}}\right\rangle \\
& \left\langle t_{2}\right\rangle=\left\langle\frac{-n_{X} n_{Y}}{a} \quad n_{Z}+\frac{n_{X}^{2}}{a}-n_{Y}\right\rangle
\end{aligned}
$$

where

$$
\mathrm{a}=1+\mathrm{n}_{\mathrm{Z}}
$$

The point $\mathrm{q}$ in the thickness is defined by

$$
\left\{\mathrm{x}_{\mathrm{q}}\right\}=\left\{\mathrm{x}_{\mathrm{p}}\right\}+\mathrm{Z}\{\mathrm{n}\}
$$

The coordinates of nodes $1,2,3$ in the local system at original 1 are

$$
\left\{\begin{array}{l}
x_{1} \\
y_{1}
\end{array}\right\}=\left\{\begin{array}{l}
0 \\
0
\end{array}\right\}, \quad\left\{\begin{array}{l}
x_{2} \\
y_{2}
\end{array}\right\}=\left[\begin{array}{ll}
t_{1} & t_{2}
\end{array}\right]^{T}\left\{\begin{array}{l}
X_{21} \\
Y_{21} \\
Z_{21}
\end{array}\right\},\left\{\begin{array}{l}
x_{3} \\
y_{3}
\end{array}\right\}=\left[\begin{array}{ll}
t_{1} & t_{2}
\end{array}\right]^{T}\left\{\begin{array}{l}
X_{31} \\
Y_{31} \\
Z_{31}
\end{array}\right\}
$$

The coordinates of a point $p$ at middle surface are

$$
\left\{x_{p}\right\}=\left\{\begin{array}{l}
x \\
y
\end{array}\right\}=\sum_{i=1}^{3} N_{i}\left\{\begin{array}{l}
x_{i} \\
y_{i}
\end{array}\right\}
$$

Expression of virtual internal work $\mathrm{W}^{\mathrm{e}}$ results from the membrane and bending effect in the local reference system

$$
\mathrm{W}_{\mathrm{int}}^{\mathrm{e}}=\mathrm{W}_{\mathrm{int}}^{\mathrm{m}}+\mathrm{W}_{\mathrm{int}}^{\mathrm{f}}=\int\left\langle\mathrm{e}^{*}\right\rangle \mathrm{NdA}+\int\left\langle\chi^{*}\right\rangle \mathrm{MdA}
$$

\subsection{Kinematic variables}

The displacement field of a point $q$ is defined by

$$
\mathrm{u}_{\mathrm{q}}^{*}=\mathrm{u}_{\mathrm{p}}^{*}+\mathrm{z} \beta^{*} \quad, \quad \frac{-\mathrm{h}}{2} \leq \mathrm{z} \leq \frac{\mathrm{h}}{2}
$$

Where $\mathrm{h}$ is the thickness of the shell, and $\beta$ the rotation 


$$
\left\{\begin{array}{c}
\mathrm{u}_{\mathrm{q}}^{*} \\
\mathrm{v}_{\mathrm{q}}^{*} \\
\mathrm{w}_{\mathrm{q}}^{*}
\end{array}\right\}=\left\{\begin{array}{c}
\mathrm{u}^{*} \\
\mathrm{v}^{*} \\
\mathrm{w}^{*}
\end{array}\right\}+\mathrm{z}\left\{\begin{array}{c}
\beta_{\mathrm{x}} \\
\beta_{\mathrm{y}} \\
0
\end{array}\right\}
$$

Displacements of membrane obtained by CST element

$$
\mathrm{u}^{*}=\left\langle\mathrm{N}_{\mathrm{u}}\right\rangle\left\{\mathrm{u}_{\mathrm{n}}^{*}\right\}, \quad \mathrm{v}^{*}=\left\langle\mathrm{N}_{\mathrm{u}}\right\rangle\left\{\mathrm{u}_{\mathrm{n}}^{*}\right\}
$$

$\left\{u_{n}{ }^{*}\right\}$ vector of the nodal variables of the element

$$
\left\{u_{n}^{*}\right\}=\left\langle\cdots\left(u_{i}^{*} \quad v_{i}^{*} \quad w_{i}^{*}\right) \cdots \text { i vary from } 1 \text { to } 3\right\rangle
$$

Rotations $\beta \mathrm{x}$ and $\beta \mathrm{y}$ relating to element DKT are

$$
\beta_{\mathrm{x}}=\left\langle\mathrm{N}_{\mathrm{x}}\right\rangle\left\{\mathrm{u}_{\mathrm{n}}^{*}\right\} \quad, \quad \beta_{\mathrm{y}}=\left\langle\mathrm{N}_{\mathrm{y}}\right\rangle\left\{\mathrm{u}_{\mathrm{n}}^{*}\right\}
$$

\subsection{Membrane deformations}

The virtual membrane deformations in terms of nodal displacements are given by

$$
\begin{aligned}
& \left\{\mathrm{e}^{*}\right\}=\left[\mathrm{B}_{\mathrm{m}}\right]\left\{\mathrm{u}_{\mathrm{n}}^{*}\right\} \\
& \left\{\mathrm{e}^{*}\right\}=\left\{\begin{array}{c}
\mathrm{u}_{, \mathrm{x}}^{*} \\
\mathrm{v}_{\mathrm{y}}^{*} \\
\mathrm{u}_{\mathrm{y}}^{*}+\mathrm{v}_{, \mathrm{x}}^{*}
\end{array}\right\}
\end{aligned}
$$

Where

$$
\begin{aligned}
& {\left[\mathrm{B}_{\mathrm{m}}\right]=\frac{1}{2 \mathrm{~A}}\left[\begin{array}{c}
\mathrm{y}_{3}\left\langle\mathrm{~N}_{\mathrm{u}, \xi}\right\rangle-\mathrm{y}_{2}\left\langle\mathrm{~N}_{\mathrm{u}, \eta}\right\rangle \\
-\mathrm{x}_{3}\left\langle\mathrm{~N}_{\mathrm{v}, \xi}\right\rangle+\mathrm{x}_{2}\left\langle\mathrm{~N}_{\mathrm{v}, \eta}\right\rangle \\
-\mathrm{x}_{3}\left\langle\mathrm{~N}_{\mathrm{u}, \xi}\right\rangle+\mathrm{x}_{2}\left\langle\mathrm{~N}_{\mathrm{u}, \eta}\right\rangle+\mathrm{y}_{3}\left\langle\mathrm{~N}_{\mathrm{v}, \xi}\right\rangle-\mathrm{y}_{2}\left\langle\mathrm{~N}_{\mathrm{v}, \eta}\right\rangle
\end{array}\right]} \\
& \mathrm{N}_{\mathrm{u}}=\left\langle\cdots \mathrm{N}_{\mathrm{i}} \quad 0 \quad 0 \ldots \text { i vary from } 1 \text { to } 3\right\rangle \\
& \mathrm{N}_{\mathrm{v}}=\left\langle\begin{array}{lll}
\cdots 0 & \mathrm{~N}_{\mathrm{i}} \quad 0 \ldots \text { i vary from } 1 \text { to } 3
\end{array}\right\rangle \\
& {\left[\mathrm{B}_{\mathrm{m}}\right]=\frac{1}{2 \mathrm{~A}}\left[\begin{array}{ccccccccc}
-\mathrm{y}_{3}+\mathrm{y}_{2} & 0 & 0 & \mathrm{y}_{3} & 0 & 0 & -\mathrm{y}_{2} & 0 & 0 \\
0 & \mathrm{x}_{3}-\mathrm{x}_{2} & 0 & 0 & -\mathrm{x}_{3} & 0 & 0 & \mathrm{x}_{2} & 0 \\
\mathrm{x}_{3}-\mathrm{x}_{2} & -\mathrm{y}_{3}+\mathrm{y}_{2} & 0 & -\mathrm{x}_{3} & \mathrm{y}_{3} & 0 & \mathrm{x}_{2} & -\mathrm{y}_{2} & 0
\end{array}\right]}
\end{aligned}
$$

\subsection{Bending deformation}

Virtual curvatures

$$
\begin{aligned}
& \left\{\chi^{*}\right\}=\left[\mathrm{B}_{\mathrm{f}}\right]\left\{\mathrm{u}_{\mathrm{n}}^{*}\right\} \\
& \left\{\chi^{*}\right\}=\left\{\begin{array}{c}
\beta_{\mathrm{x}, \mathrm{x}}^{*} \\
\beta_{\mathrm{y}, \mathrm{y}}^{*} \\
\beta_{\mathrm{x}, \mathrm{y}}^{*}+\beta_{\mathrm{y}, \mathrm{x}}^{*}
\end{array}\right\},\left[\mathrm{B}_{\mathrm{f}}\right]=\frac{1}{2 \mathrm{~A}}\left[\begin{array}{c}
\mathrm{y}_{3}\left\langle\mathrm{~N}_{, \xi}^{\mathrm{x}}\right\rangle-\mathrm{y}_{2}\left\langle\mathrm{~N}_{, \eta}^{\mathrm{x}}\right\rangle \\
-\mathrm{x}_{3}\left\langle\mathrm{~N}_{, \xi}^{\mathrm{y}}\right\rangle+\mathrm{x}_{2}\left\langle\mathrm{~N}_{, \eta}^{\mathrm{y}}\right\rangle \\
-\mathrm{x}_{3}\left\langle\mathrm{~N}_{, \xi}^{\mathrm{x}}\right\rangle+\mathrm{x}_{2}\left\langle\mathrm{~N}_{, \eta}^{\mathrm{x}}\right\rangle+\mathrm{y}_{3}\left\langle\mathrm{~N}_{, \xi}^{\mathrm{y}}\right\rangle-\mathrm{y}_{2}\left\langle\mathrm{~N}_{, \eta}^{\mathrm{y}}\right\rangle
\end{array}\right]
\end{aligned}
$$


In the vectors $\mathrm{N}$ only the terms of the bending are considered (the terms of rotation are null)

$$
\begin{aligned}
& \mathrm{N}^{\mathrm{x}}=\left\langle\begin{array}{lllllllll}
0 & 0 & \mathrm{~N}_{11}^{\mathrm{x}} & 0 & 0 & \mathrm{~N}_{21}^{\mathrm{x}} & 0 & 0 & \mathrm{~N}_{31}^{\mathrm{x}}
\end{array}\right\rangle \\
& \mathrm{N}^{\mathrm{y}}=\left\langle\begin{array}{lllllllll}
0 & 0 & \mathrm{~N}_{11}^{\mathrm{y}} & 0 & 0 & \mathrm{~N}_{21}^{\mathrm{y}} & 0 & 0 & \mathrm{~N}_{31}^{\mathrm{y}}
\end{array}\right\rangle \\
& \mathrm{N}^{\mathrm{x}}{ }_{11} \mathrm{~N}^{\mathrm{x}}{ }_{21} \mathrm{~N}^{\mathrm{x}}{ }_{31} \text { and } \mathrm{N}_{11}^{\mathrm{y}} \mathrm{N}^{\mathrm{y}}{ }_{21} \mathrm{~N}_{31}^{\mathrm{y}} \text { are given by } \\
& \mathrm{N}_{\mathrm{i} 1}^{\mathrm{x}}=\frac{3}{2 \mathrm{~L}_{\mathrm{k}}} \mathrm{P}_{\mathrm{k}} \mathrm{C}_{\mathrm{k}}-\frac{3}{2 \mathrm{~L}_{\mathrm{m}}} \mathrm{P}_{\mathrm{m}} \mathrm{C}_{\mathrm{m}}, \quad \mathrm{N}_{\mathrm{i} 1}^{\mathrm{y}}=\frac{3}{2 \mathrm{~L}_{\mathrm{k}}} \mathrm{P}_{\mathrm{k}} \mathrm{S}_{\mathrm{k}}-\frac{3}{2 \mathrm{~L}_{\mathrm{m}}} \mathrm{P}_{\mathrm{m}} \mathrm{S}_{\mathrm{m}}
\end{aligned}
$$

The indices of $\mathrm{k}$ and $\mathrm{m}$ are relative to the two sides having the summit $\mathrm{i}$ common point are given by Table $1, \mathrm{P}_{\mathrm{k}}$ and $\mathrm{P}_{\mathrm{m}}$ are defined by Table 2 .

Table 1. Indices $\mathrm{k}$ and $\mathrm{m}$

\begin{tabular}{llll}
\hline & Summit Nodes i & Side k (i-j) & Side m (i-j) \\
\hline & 1 & $4(1-2)$ & $6(3-1)$ \\
\hline
\end{tabular}

Table 2. Values of $\mathrm{P}_{\mathrm{K}}$ and $\mathrm{P}_{\mathrm{m}}$

\begin{tabular}{ll}
\hline & $\mathrm{P}_{\mathrm{k}}$ \\
\hline & $(\mathrm{k}=4$ to 6$)$ \\
& $\mathrm{P} 4=4 \xi \lambda$ \\
\hline
\end{tabular}

$$
C_{k}=\frac{x_{i j}}{L_{k}}, \quad S_{k}=\frac{y_{i j}}{L_{k}}, \quad L_{k}=\left(x_{i j}^{2}+y_{i j}^{2}\right)^{\frac{1}{2}}
$$

\subsection{The internal work}

$$
\mathrm{W}_{\mathrm{int}}^{\mathrm{e}}=\left\langle\mathrm{u}_{\mathrm{n}}\right\rangle[\mathrm{K}]\left\{\mathrm{u}_{\mathrm{n}}\right\}
$$

The stiffness matrix is

$$
\begin{aligned}
& {[\mathrm{K}]=\left[\mathrm{K}_{\mathrm{m}}\right]+\left[\mathrm{K}_{\mathrm{f}}\right]} \\
& {\left[\mathrm{K}_{\mathrm{m}}\right]=\mathrm{A}\left[\mathrm{B}_{\mathrm{m}}\right]^{\mathrm{T}}\left[\mathrm{H}_{\mathrm{m}}\right]\left[\mathrm{B}_{\mathrm{m}}\right]} \\
& {\left[\mathrm{K}_{\mathrm{f}}\right]=\mathrm{A}\left[\mathrm{B}_{\mathrm{f}}\right]^{\mathrm{T}}\left[\mathrm{H}_{\mathrm{f}}\right]\left[\mathrm{B}_{\mathrm{f}}\right]}
\end{aligned}
$$


where $\mathrm{H}_{\mathrm{m}}$ and $\mathrm{H}_{\mathrm{f}}$ : matrix of homogenized behavior of membrane and bending effects

$$
\begin{aligned}
& {\left[\mathrm{H}_{\mathrm{f}}\right]=\frac{E h^{3}}{12\left(1-v^{2}\right)}\left[\begin{array}{ccc}
1 & v & 0 \\
v & 1 & 0 \\
0 & 0 & \frac{1-v}{2}
\end{array}\right]} \\
& {\left[\mathrm{H}_{\mathrm{m}}\right]=\frac{\mathrm{Eh}}{\left(1-v^{2}\right)}\left[\begin{array}{ccc}
1 & v & 0 \\
v & 1 & 0 \\
0 & 0 & \frac{1-v}{2}
\end{array}\right]}
\end{aligned}
$$

E and $v$ are respectively the Young modulus and the Poisson's ratio, the resulting normal force and bending moment are

$$
[\mathrm{N}]=\left[\mathrm{H}_{\mathrm{m}}\right]\{\mathrm{e}\}, \quad[\mathrm{M}]=\left[\mathrm{H}_{\mathrm{f}}\right]\{\chi\}
$$

\section{Results and Discussion}

To test the efficiency and the performance of the developed element DKT18RF, the following various cases of applications in the field of the structures are performed.

\subsection{Clamped cylindrical shell with rigid diaphragm}

The clamped cylindrical shell shown in Fig. 2 is subjected to two diametrically opposed concentrated loads, and supported by two rigid diaphragms. The details of the geometry, loadings, materials, the boundary and symmetry conditions are given in the same figure. This test case is frequently used to evaluate the behavior of the shell finite element for simulated complex membrane states with a significant share of bending without the extension of the average surface. One-eighth of the shell is modeled by the finite element DKT18RF by using a regular mesh elements $\mathrm{N}=2,4,6$. The displacements $\mathrm{W}_{\mathrm{C}}$ and $\mathrm{V}_{\mathrm{D}}$ at points $\mathrm{C}$ and $\mathrm{D}$ are given in Tables 3 and 4 respectively. The results obtained are compared with the reference solution given by Lindberg et al. (1969) and those of elements DKT12 and DKT18 cited above. Fig. 3 shows the deformed shape of the cylinder under the applied loading.



Fig. 2. Clamped cylindrical shell with rigid diaphragm 
Table 3. Value of the bending displacements $\overline{\mathrm{W}}_{\mathrm{c}}=-\mathrm{Eh} \mathrm{W}_{\mathrm{c}} / \mathrm{P}$

\begin{tabular}{llll}
\hline Meshes (elements) & DKT18RF & $\begin{array}{l}\text { DKT18(Batoz \& } \\
\text { Dhatt, 1992) }\end{array}$ & $\begin{array}{l}\text { DKT12 } \\
\text { (Batoz \& Dhatt, 1992) }\end{array}$ \\
\hline $2 \times 2$ & 10,71 & 10,65 & 10,72 \\
$4 \times 4$ & 125,34 & 80,86 & 114,03 \\
$6 \times 6$ & 150,14 & 122,13 & 196,44 \\
\hline $\begin{array}{l}\text { Reference solution } \\
\text { (Lindberg et al., 1969) }\end{array}$ & & 164,24 & \\
\hline
\end{tabular}

Table 4. Value of $\bar{V}_{\mathrm{D}}=\mathrm{Eh} \mathrm{V}_{\mathrm{D}} / \mathrm{P}$

\begin{tabular}{llll}
\hline Meshes & DKT18RF & $\begin{array}{l}\text { DKT18(Batoz \& } \\
\text { Dhatt, 1992) }\end{array}$ & $\begin{array}{l}\text { DKT12 } \\
\text { (Batoz \& Dhatt, 1992) }\end{array}$ \\
\hline 2X2 & 1,02 & 1,01 & 1,02 \\
4X4 & 6,21 & 4,11 & 5,68 \\
6X6 & 4,37 & 4,17 & 6,06 \\
\hline Reference solution & \multicolumn{3}{c}{} \\
(Lindberg et al., 1969) & & 4,11 & \\
\hline
\end{tabular}

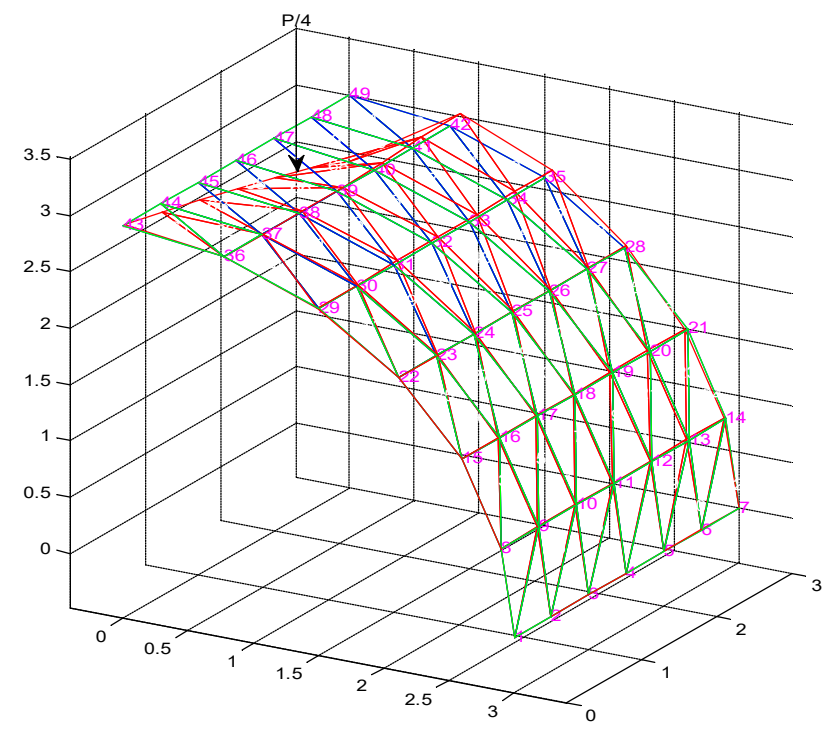

Fig. 3. Deformed shape of the clamped cylindrical shell (meshes 6x6)

The analysis of the results obtained by element DKT18RF for this case test shows a monotonous convergence of the vertical displacements at the point $\mathrm{C}$. This result shows the good performance for this element.

\subsection{Pinched cylinder with free edges}

Another test case widely used to study the shell finite elements is that of the pinched cylinder with free edge. This case test makes it possible to evaluate the convergence, performances and the representation of the rigid body mode. One-eighth of the shell is studied by the element DKT18RF with different types of mesh, the geometry, the characteristics of the material as well as the boundary conditions and symmetries are exposed in Fig. 4, where can distinguish two different cases of loading and thickness. The vertical displacement results $\mathrm{Wc}$ at point $\mathrm{C}$ are reported in Tables 5 and 6 are compared with the reference solution given by Macneal and Harder (1985) as well as the results obtained by other finite elements (Hamadi et al., 2016; Belarbi, 2000; Cantin \& Clough, 1968; Bogner et al., 1967; 
Ashwell \& Sabir, 1972; Sabir \& Lock, 1972). Fig. 5 shows the deformed shape of pinched cylinder with free edges.

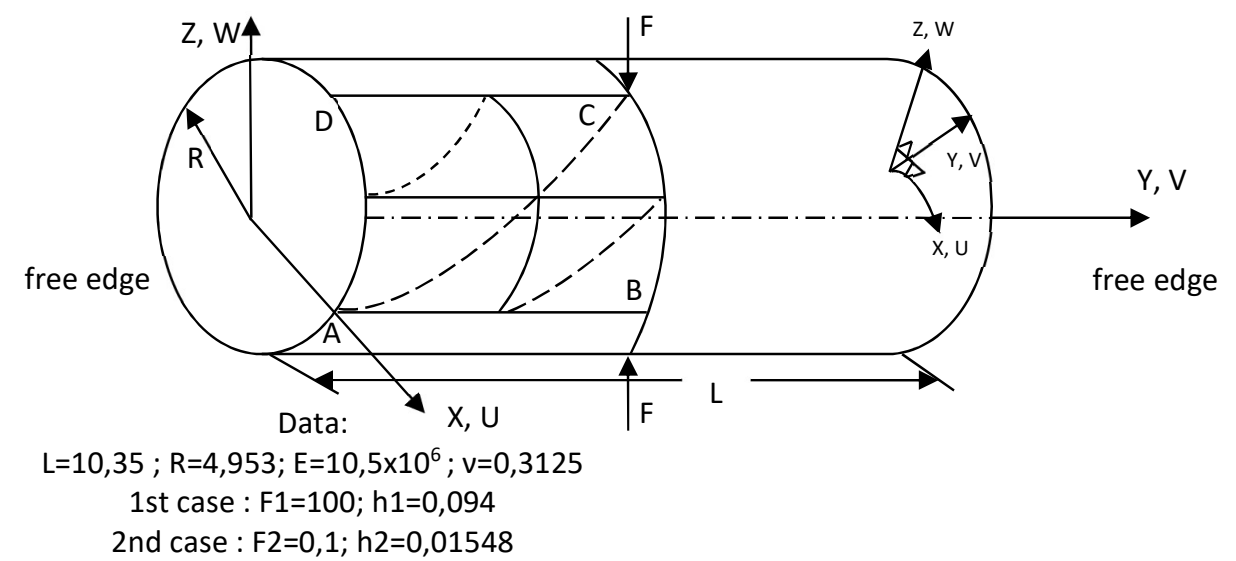

Fig. 4. Pinched cylinder with free edges

Table. 5 Value of Wc 1st case: F1=100; h1=0,094

\begin{tabular}{lllllll}
\hline Meshes & $\begin{array}{c}\text { (Bogner et } \\
\text { al., 1967) }\end{array}$ & $\begin{array}{c}\text { (Cantin \& } \\
\text { Clough, 1968) } \\
\text { with RBM }\end{array}$ & $\begin{array}{c}\text { (Cantin \& } \\
\text { Clough, 1968) } \\
\text { Without RBM }\end{array}$ & $\begin{array}{c}\text { ACM_SBQ4 } \\
\text { (Belarbi, } \\
2000)\end{array}$ & $\begin{array}{c}\text { ACM_RSBE5 } \\
\text { (Hamadi et al., } \\
\text { 2016) }\end{array}$ & DKT18RF \\
\hline $1 \times 1$ & 0.0025 & - & - & 0.0860 & 0.08763 & 2,7500 \\
$1 \times 3$ & 0.1026 & 0.0297 & 0.0009 & 0.1041 & 0.1060 & 0,7255 \\
$1 \times 4$ & 0.1087 & - & - & - & 0.1100 & - \\
$1 \times 5$ & - & 0.0769 & 0.0021 & 0.1090 & 0.1116 & 0,4077 \\
$1 \times 7$ & - & 0.0987 & 0.0035 & 0.1102 & 0.1129 & 0,2666 \\
$1 \times 8$ & - & - & - & - & 0.1132 & 0,2209 \\
$1 \times 9$ & - & 0.1057 & 0.0051 & 0.1115 & 0.1134 & 0,1852 \\
$2 \times 9$ & - & - & - & - & - & 0,1449 \\
$3 \times 9$ & - & - & - & - & - & 0,1153 \\
\hline Reference solution (Macneal and Harder, 1985) & \multicolumn{2}{c}{0,1139} \\
\hline
\end{tabular}

Table 6. Value of Wc 2 nd case: $\mathrm{F} 2=0,1 ; \mathrm{h} 2=0,01548$

\begin{tabular}{lllllll}
\hline Meshes & $\begin{array}{c}\text { (Ashwell \& } \\
\text { Sabir, } \\
1972)\end{array}$ & $\begin{array}{c}\text { (Cantin \& } \\
\text { Clough, 1968) }\end{array}$ & $\begin{array}{c}\text { (Sabir \& } \\
\text { Lock, } \\
1972)\end{array}$ & $\begin{array}{c}\text { ACM_SBQ4 } \\
\text { (Belarbi, } \\
2000)\end{array}$ & $\begin{array}{c}\text { ACM_RSBE5 } \\
\text { (Hamadi et al., } \\
2016)\end{array}$ & DKT18RF \\
\hline $1 \times 1$ & 0.02301 & 0.00001 & 0.00001 & 0.01922 & 0.0196 & 0,61673 \\
$1 \times 3$ & 0.02302 & 0.00001 & 0.00001 & 0.02302 & 0.02343 & 0,16161 \\
$1 \times 4$ & 0.02403 & 0.00074 & 0.00063 & - & - & - \\
$1 \times 5$ & - & - & - & 0.02387 & - & 0,08830 \\
$1 \times 7$ & - & - & - & 0.02418 & - & 0,05539 \\
$2 \times 4$ & 0.02409 & 0.00070 & 0.00064 & - & - & - \\
$3 \times 4$ & 0.02414 & 0.00068 & 0.00065 & - & - & - \\
$2 \times 7$ & - & - & - & - & - & 0,03488 \\
$3 \times 7$ & - & - & - & - & - & 0,02539 \\
\hline
\end{tabular}


The results obtained by the DKT18RF element can be considered satisfactory for both cases. The convergence of the element towards the reference solution can be guaranteed by refining the meshes.

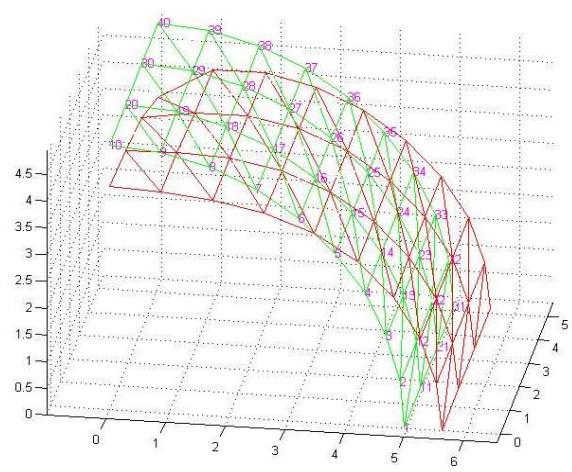

Fig. 5. Deformed shape of pinched cylinder with free edges (meshes $3 \times 9)$
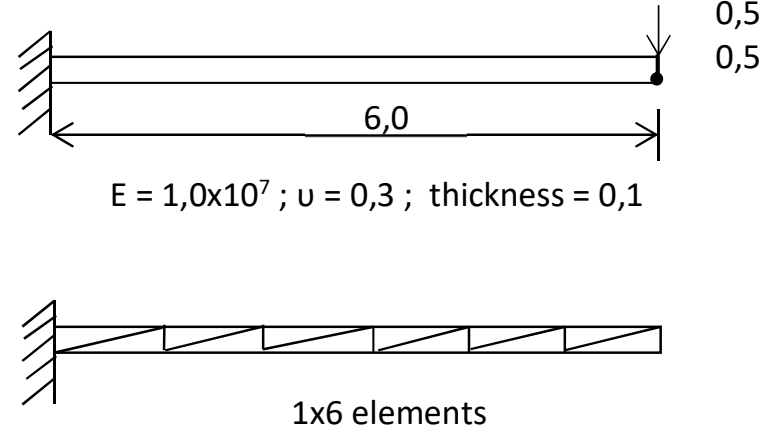

Fig. 6. Cantilever beam subjected to a point load its free end

\subsection{Cantilever beam}

A cantilever beam is clamped at one end and charged at the other free end as shown in Fig. 6. The values of the load, Young modulus, Poisson's ratio and the thickness are given on the same figure. This case test is a standard problem to test the efficiency of the finite elements (Macneal \& Harder, 1985).

Fig. 7 shows the results obtained for the deflection at point A. These values are calculated by the use of different meshes with the DKT18RF element and are compared with the reference solution (Macneal \& Harder, 1985) and with other finite elements Q4 (the standard four-node isoparametric element), and Q4SBE1 (Hamadi, 2006), SBRIE (Sabir \& Salhi, 1986), SBRIE2 (Sabir \& Sfendji, 1995). It can be observed that the convergence is monotone and the closed form solution can be obtained with the increased number of elements used. The deformed shape of the cantilever beam is represented in Fig. 8.

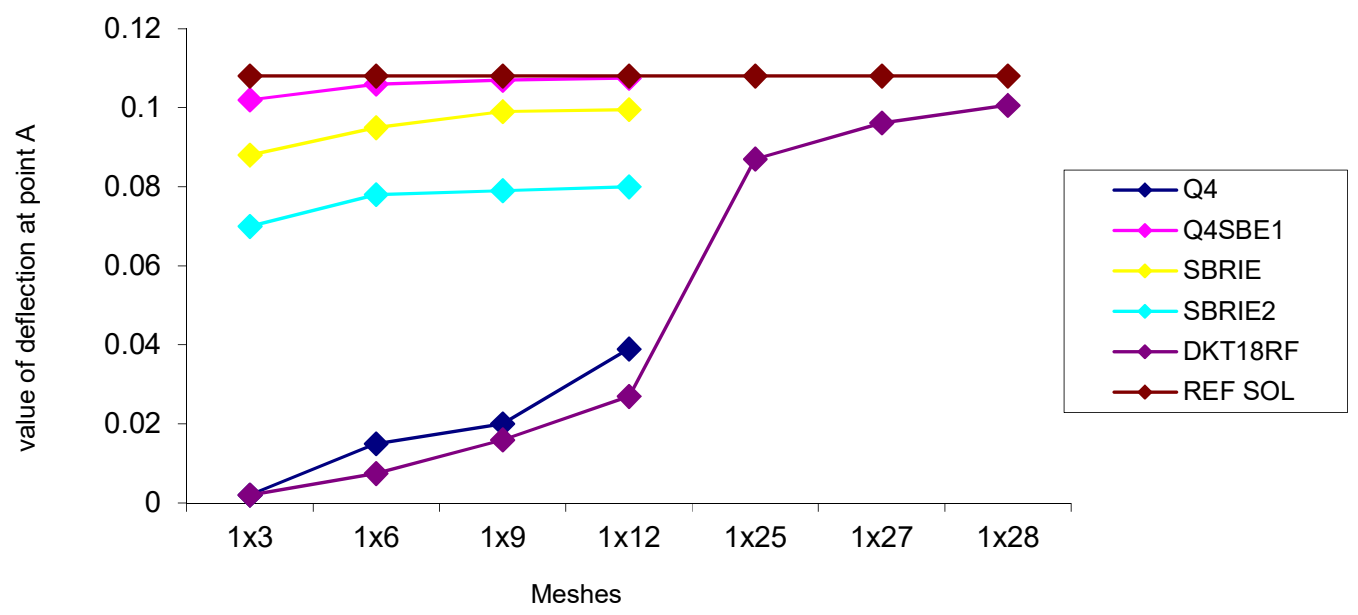

Fig. 7. Curve of convergence of displacement at the point A

Fig. 7 shows the monotone convergence curve of the element DKT18RF and good results can be obtained with the increased number of meshes. 


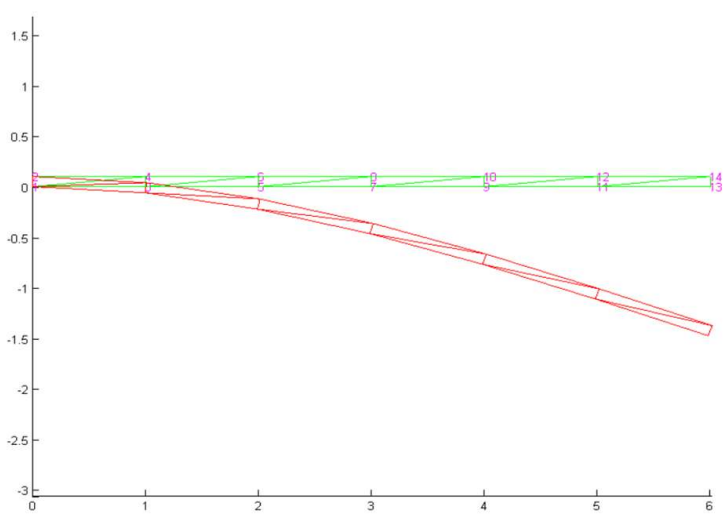

Fig. 8. Deformed shape of a cantilever beam (meshes $1 \times 6)$

\section{Conclusion}

In this paper the developed rotation free shell finite element is presented. The formulated element is obtained by using superposition of the membrane element CST with constant deformations and the modified discrete Kirchhoff element DKT. The modified element have only one translation nodal variable $(w)$, which endow with a shell finite element with three translations per node $(\mathrm{u}, \mathrm{v}, \mathrm{w})$. The good performance of formulated element DKT18RF is examined through the validation tests presented in part 3 of this paper.

Monotonous convergence towards the reference solution was clearly observed. The absence of rotation does not affect on the quality of the results obtained, even so it is remarkable in case tests 2 and 3 that it is required to refined meshes to obtain the closed form solution. Besides of convergence is slow, we can say that the element remains always effective considering it is conceive mainly to solve the problem of connection in the zone of junction between the thin and thick structures.

Finally, from this work we can see in perspective the idea of formulation a finite shell type element usable for thin and thick structures from the element DKT18RF.

\section{Acknowledgements}

The authors wish to acknowledge kind supports provided by university of Biskra.

\section{References}

Abed-Meraim, F., \& Combescure, A. (2002). SHB8PS-a new adaptative, assumed-strain continuum mechanics shell element for impact analysis. Computers \& Structures, 80(9-10), 791-803.

Ahmad, S., Irons, B. M., \& Zienkiewicz, O. C. (1970). Analysis of thick and thin shell structures by curved finite elements. International Journal for Numerical Methods in Engineering, 2(3), 419-451.

Ashwell, D. G., \& Sabir, A. B. (1972). A new cylindrical shell finite element based on simple independent strain functions. International Journal of Mechanical Sciences, 14(3), 171-183.

Batoz, J. L., \& Dhatt, G. (1992) Modélisation des Structures par Eléments Finis, vol. 3. Paris: Hermès.

Belarbi, M. T. (2000). Développement de nouveaux éléments finis basés sur le modèle en déformation. Application linéaire et non linéaire (Doctoral dissertation, Thèse de Doctorat d'état, Université de Constantine).

Bogner, F. K., Fox, R. L., \& Schmit, L. A. (1967). A cylindrical shell discrete element. AIAA Journal, 5(4), 745-750. 
Brunet, M., \& Sabourin, F. (1994). Prediction of necking and wrinkles with a simplified triangular shell element in sheet forming. In Proceedings on the Int. Conf. on Metal Forming Process Simulation in Industry, p75-93, Baden-Baden, Germany.

Brunet, M., \& Sabourin, F. (1995). A simplified triangular shell element with a necking criterion for 3D sheet-forming analysis. Journal of Materials Processing Technology, 50(1-4), 238-251.

Cantin, G., \& Clough, R. W. (1968). A curved, cylindrical-shell, finite element. AIAA Journal, 6(6), 1057-1062.

Crisfield, M. A., \& Peng, X. (1992). Efficient nonlinear shell formulations with large rotations and plasticity. DRJ Owen et al. Computational Plasticity: Models, Software and Applications, Part, 1, 1979-1997.

Guo, Y. Q., Gati, W., Naceur, H., \& Batoz, J. L. (2002). An efficient DKT rotation free shell element for springback simulation in sheet metal forming. Computers \& structures, 80(27-30), 2299-2312.

Hamadi, D. (2006). Analysis of structures by non-conforming finite elements (Doctoral dissertation, $\mathrm{PhD}$ Thesis, Civil engineering department, Biskra University, Algeria).

Hamadi, D., Ayoub, A., \& Abdelhafid, O. (2015). A new flat shell finite element for the linear analysis of thin shell structures.European Journal of Computational Mechanics, 24(6), 232-255.

Lindberg, G. M., Olson, M. D., \& Cowper, G. R. (1969). New developments in the finite element analysis of shells. Quarterly Bulletin of the Division of Mechanical Engineering and The National Aeronautical Establishment, 4, 1-38.

Macneal, R. H., \& Harder, R. L. (1985). A proposed standard set of problems to test finite element accuracy. Finite Elements in Analysis and Design, 1(1), 3-20.

Mercier, F. (1998). Contribution à la modélisation de l'emboutissage de tôles minces par l'approche inverse (Doctoral dissertation, Université de Technologie de Compiègne).

Morley, L. S. D. (1971). The constant-moment plate-bending element. Journal of Strain Analysis, 6(1), 20-24.

Oñate, E., Agelet de Saracibar, C., \& Dalin, J. B. (1989). Finite element analysis of sheet metal forming problems using a selective voided viscous shell membrane formulation. InProceedings of the 4th International Conference on Numerical Methods in Industrial Forming Processes: NUMIFORM (Vol. 89, pp. 23-30).

Oñate, E., \& Flores, F. G. (2005). Advances in the formulation of the rotation-free basic shell triangle. Computer Methods in Applied Mechanics and Engineering, 194(21-24), 2406-2443.

Oñate, E., Flores, F. G., \& Neamtu, L. (2007). Enhanced rotation-free basic shell triangle. Applications to sheet metal forming. In Computational Plasticity (pp. 239-265). Springer, Dordrecht.

Rio, G., Tathi, B., \& Horkay, F. (1993). Introducing bending rigidity in a finite element membrane sheet metal forming model. Int. Sem. Mecamat, 91, 449.

Sabir, A. B., \& Lock, A. C. (1972). A curved, cylindrical shell, finite element. International Journal of Mechanical Sciences, 14(2), 125-135.

Sabir, A. B., \& Salhi, H. Y. (1986). A strain based finite element for general plane elasticity problems in polar coordinates. Research Mechanica, 19(1), 1-16.

Sabir, A. B., \& Sfendji, A. (1995). Triangular and rectangular plane elasticity finite elements. ThinWalled Structures, 21(3), 225-232.

Sabourin, F., \& Brunet, M. (2006). Detailed formulation of the rotation-free triangular element "S3" for general purpose shell analysis. Engineering Computations, 23(5), 469-502.

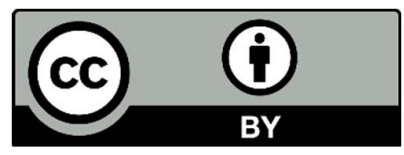

(C) 2020 by the authors; licensee Growing Science, Canada. This is an open access article distributed under the terms and conditions of the Creative Commons Attribution (CC-BY) license (http://creativecommons.org/licenses/by/4.0/). 